\title{
Fisheries and trade of seahorses, Hippocampus spp., in southern India
}

\author{
K. R. SALIN \& T.M. YOHANNAN \\ Calicut Research Centre of Central Marine Fisheries Research Institute, Calicut, Kerala, India
}

\author{
C. MOHANAKUMARAN NAIR \\ College of Fisheries, Panangad, Kochi, Kerala, India
}

\begin{abstract}
Seahorses (Hippocampus spp.) are a major commodity fished from the shallow coastal seas of the south coast of India where there is an abundance of sea grasses, sponges and corals. They are in great demand for export as traditional medicines, curios and aquarium fish. Organised fishing and trade of seahorses exists in India along the Palk Bay and Gulf of Mannar coasts. At the Palk Bay coast, seahorses are targeted by divers along with sea cucumbers (Holothuria spp.) and gastropods (e.g. Murex spp., Xancus pyrum Hornell). In the Gulf of Mannar, most of the seahorses are landed as bycatch of shrimp trawling. Seahorses are also fished from Kerala as a bycatch of trawling, although no organised fishery and trade exists. Five species of seahorses were identified from the Palk Bay coast, whereas only two species were obtained from Kerala. Most seahorses from India are exported to Singapore, Hong Kong, Malaysia and the United Arab Emirates. The volume of dried seahorse trade from India was estimated to be $9.75 \mathrm{t}$ as derived from catch data in 2001, which was much higher than official statistics of $4.34 \mathrm{t}$ during 2001-2002, suggesting the major part of the exports might be through non-conventional means and goes undeclared. Some aspects of the impact of large-scale fishing and trade on conservation of these seahorses are discussed.
\end{abstract}

KEYWORDS: conservation, fishery, Hippocampus, India, seahorses, trade.

\section{Introduction}

Seahorses (Hippocampus spp.) are in much demand for traditional medicines and curios in dried form, and as aquarium fish when alive. Shallow seas abundant in sea grasses, sponges and corals characterise the natural habitats of the seahorses (Vincent 1994, 1995).

All seahorses (Syngnathidae) belong to one genus Hippocampus. There are about 33 species of seahorses worldwide (Lourie, Vincent \& Hall 1999; Lourie \& Randall 2003). Seahorses are unique in their reproductive behaviour, in which the males become pregnant. The male fertilises and broods the eggs produced and deposited into its pouch by the female during courtship and mating, and in turn delivers the hatchling, after a long period of pregnancy and labour. Most species of seahorses studied so far show unique sexual fidelity and form faithful pair bonds (Vincent \& Sadler 1995), in which case one male and one female mate repeatedly and exclusively giving up opportunities to interact with non-partners.

The world trade of dried seahorses was estimated to be over 20 million individuals (Vincent 1996). The trade has been expanding globally at a fast pace and the demand exceeds supply. India has a long history of trade on seahorses, which originated along the southeast coast, particularly in the state (province) of Tamil Nadu. Limited quantities of seahorses were also reported to be collected from the coast of Kerala, and off Maharashtra and Karnataka (Vincent 1996). A well-established seahorse trade emerged along the south Tamil Nadu coast, especially the Palk Bay and Gulf of Mannar areas, as an alternate fishery to the dwindling resources of sea cucumber (Holothuria spp.) along these coasts (Marichamy, Lipton, Ganapathy \& Ramalingam 1993).

Vincent (1996) reported that about $3.6 \mathrm{t}$ of seahorses were dried for export from India during 1995. 
According to official estimates (Anonymous 2003), about $2.53 \mathrm{t}$ of seahorses worth 1.5 million rupees (US\$ 40 000) were exported from India during 20002001, mainly to Singapore, United Arab Emirates and Hong Kong. This increased to $4.34 \mathrm{t}$ during 20012002, worth 2.673 million rupees (US\$ 70000 ), with Chennai being the major port of activity.

Despite the existence of a flourishing trade, the study of Indian seahorses has attracted little interest. In the present study, the features of the seahorse fishery in the south coast of India were explored, and the trade of these fish was assessed based on trade interviews and catch data from Thondi, one of the major areas of seahorse landing at the south Tamil Nadu coast. The exploitation from one of the major landing centres in the state of Kerala, Sakthikulangara harbour, was also estimated, although there is no organised fishery and trade of seahorses in Kerala.

The biology of seahorses renders them particularly vulnerable to habitat loss and overexploitation (Foster \& Vincent 2004). Ten species of seahorse are listed as 'vulnerable' or 'endangered' on the 2004 IUCN Red List of Threatened Species (IUCN 2004). The entire genus Hippocampus has now been added to Appendix II of Convention on International Trade in Endangered Species of Wild Fauna and Flora (CITES) (McPherson \& Vincent 2004). There has been a growing concern on conservation of seahorses in India, which culminated in the prohibition of capture of wild seahorses in 2001. This signalled almost the end of a sizeable trade of Indian seahorses from 2002 onwards leaving the fate of thousands of fishers, who relied primarily on seahorses for their living, at stake. The paper discusses some strategies for conservation of seahorses along the Indian coast.

\section{Materials and methods}

The landings of seahorses along the different centres in Palk Bay and Gulf of Mannar coasts were assessed by a resource survey. Periodic random sampling was carried out at Thondi, which was the major fishing area for seahorses in Palk Bay. Seahorse fishing at Thondi was carried out by small groups of six to eight divers in boats, and by fishers in small motorised crafts using a mini bottom trawl. In the Gulf of Mannar, the majority were taken as bycatch from shrimp trawlers. During 2001, monthly landing data of seahorses from five randomly selected boats were collected according to sex, for five consecutive days, between the 10th and 20 th of the month. The number of boats in operation on the 5 days of observation was noted and then the mean number of boats fishing on each day of that month was determined. The total number of seahorses caught in 2001 was then computed as the product of the mean daily catch, the mean number of boats operating daily and the total number of days of fishing in a month, and summing the catches for each month.

Interviews with the two major wholesale buyers of seahorses in Chennai, and several other local intermediaries were used to understand the percentage share of Thondi in the total landings of seahorses from Palk Bay and Gulf of Mannar. Total landings at Thondi were estimated to be $68 \%$ of the total landing from Palk Bay, while Palk Bay in turn contributed $76 \%$ of the total landing from the south Tamil Nadu coast. Based on the assumption that this is representative of the landing from the entire coast of India because of the absence of an organised trade in any other place, the total trade of seahorses in India was calculated.

Regular samples were also collected from Sakthikulangara harbour on 2 days in the first and third weeks of each month during 2001, but maintaining an interval of 13-16 days between the two data collections. Each day, data on catch by sex were collected from 10 boats systematically in the order of their landing. The estimation of total catch was the same as for the Thondi area. Occasional samples were also gathered from some of the important landing centres of Kerala to determine the species composition of those areas. The mean wet weight (g, using a portable digital balance) and wet length $(\mathrm{mm})$ of all the samples from Thondi and Sakthikulangara were measured immediately after they were collected. The seahorse specimens collected from different centres were then segregated source wise, dried and species identification was carried out based on the detailed key and seahorse measurement protocol provided by Lourie et al. (1999).

\section{Results}

The total landing of seahorses at Thondi (Fig. 1), the major fishing centre at Palk Bay, was estimated to be approximately 1368000 individuals (Table 1). The mean wet length and weight of the landed seahorses (assorted species) were $11.5 \pm 2.36 \mathrm{~cm}$ and $6.89 \pm 2.04 \mathrm{~g}(n=853)$ respectively. Thus, the total landing from Thondi was estimated as $9.43 \mathrm{t} \mathrm{yr}^{-1}$. The major fishery occurred from May to October, with a peak in August. About 700 boats were in operation along both the coasts. Fishing was managed by small co-operatives consisting of six to eight fishers, who shared the profit. The landing of seahorses was more abundant from the Palk Bay region where the fishing season was influenced by the prevailing weather. When 


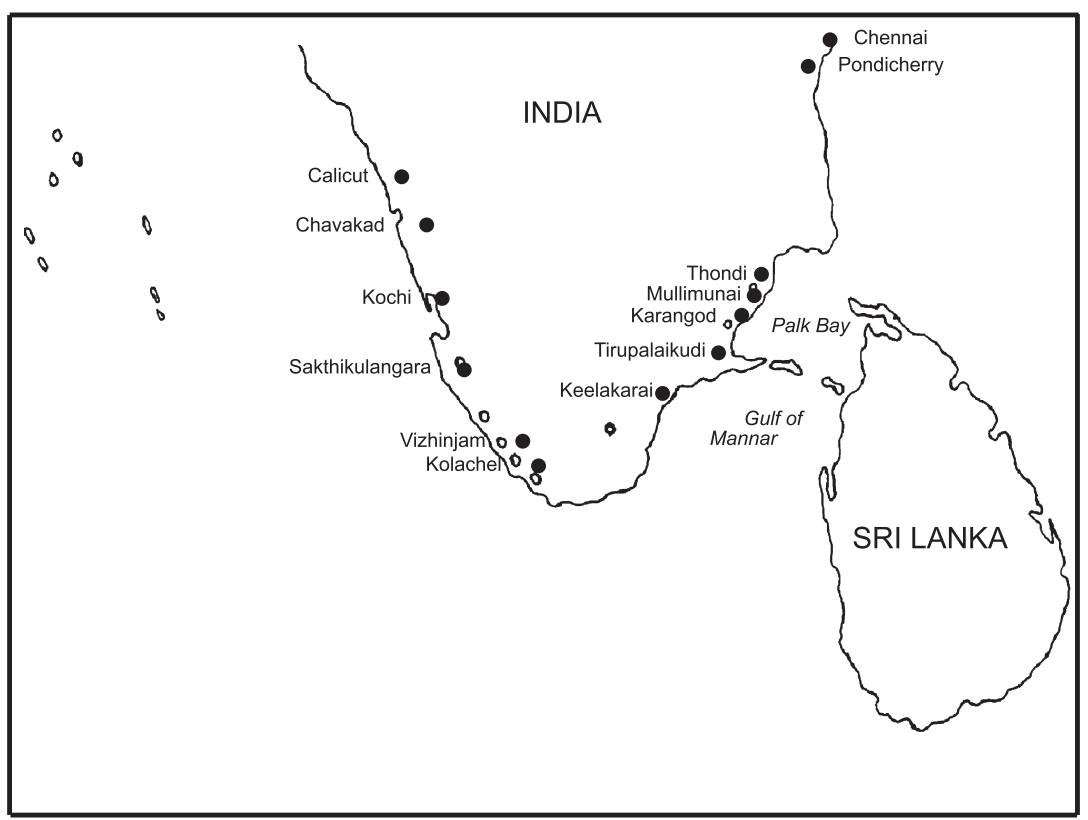

Figure 1. Map of the south coast of India depicting the areas of seahorse availability.

the sea was rough, diving was difficult and seahorses were mainly landed as bycatch from trawlers.

Given that $68 \%$ of the total landings of Palk Bay came from Thondi, the total catch of seahorses in Palk Bay was estimated as 2012616 individuals (13.867 t). It was also assumed that $76 \%$ of the total landing from the south Tamil Nadu coast came from Palk Bay, thus, the total combined annual catch of seahorses from the Gulf of Mannar and Palk Bay, which represented the total trade from India, was estimated as 2648179 individuals (18.246 t). Assuming a yield of $53.45 \%$ when the seahorses were dried for export (Marichamy et al. 1993), the total quantity of dried seahorses that constituted the export trade from India was estimated to be $9.75 \mathrm{t}$ during 2001 .

In Kerala, most of the small quantities of seahorses landed came from Sakthikulangara and Vizhinjam harbours. There was no organised fishery for seahorses in any of the fish landing centres in Kerala. In the Sakthikulangara area, the quantities landed were highest in the trawl bycatch during November and December (Table 2), coinciding with the north-east monsoon rains. The number of trawlers in operation at this harbour, varied from 915 to 2580 per day, and the quantities landed were high. The landings at Sakthikulangara consisted of smaller sized seahorses of

Table 1. Estimates of catch (number) and catch per effort from Thondi during 2001

\begin{tabular}{|c|c|c|c|c|}
\hline Months & $\begin{array}{l}\text { Catch per boat per day } \\
\quad(\text { mean } \pm \text { SD) }\end{array}$ & $\begin{array}{l}\text { Total days of } \\
\text { fishing per month }\end{array}$ & $\begin{array}{l}\text { Total number of } \\
\text { boats per day }\end{array}$ & $\begin{array}{l}\text { Total number of } \\
\text { seahorses caught }\end{array}$ \\
\hline January & $14.4 \pm 6.8$ & 27 & 31 & 12053 \\
\hline February & $28.8 \pm 15.9$ & 24 & 29 & 20017 \\
\hline March & $21.6 \pm 9.0$ & 19 & 24 & 9850 \\
\hline April & $17.2 \pm 4.7$ & 24 & 19 & 7843 \\
\hline May & $43.2 \pm 8.4$ & 27 & 26 & 30298 \\
\hline June & $244.8 \pm 24.8$ & 25 & 41 & 250879 \\
\hline July & $284.1 \pm 49.5$ & 27 & 56 & 429589 \\
\hline August & $325.5 \pm 13.7$ & 26 & 56 & 473899 \\
\hline September & $48.0 \pm 15.6$ & 26 & 46 & 57408 \\
\hline October & $52.8 \pm 18.8$ & 27 & 42 & 59875 \\
\hline November & $21.8 \pm 5.1$ & 17 & 15 & 5549 \\
\hline December & $21.0 \pm 9.3$ & 20 & 27 & 11318 \\
\hline Total annual landing & & & & 1368579 \\
\hline
\end{tabular}


Table 2. Annual landing of seahorses by shrimp trawlers of Sakthikulangara harbour during 2001

\begin{tabular}{|c|c|c|c|c|}
\hline Months & $\begin{array}{l}\text { Catch per boat per month } \\
\quad(\text { mean } \pm \text { SD })\end{array}$ & $\begin{array}{l}\text { Mean number of } \\
\text { boats per month }\end{array}$ & $\begin{array}{c}\text { Sex ratio } \\
\text { (male:female) }\end{array}$ & $\begin{array}{l}\text { Total number of } \\
\text { seahorses caught }\end{array}$ \\
\hline January & $11.7 \pm 0.83$ & 1578 & $1.25: 1$ & 18463 \\
\hline February & $16.25 \pm 0.88$ & 1633 & $1: 1.6$ & 26536 \\
\hline March & $12.6 \pm 0.83$ & 1650 & $1: 1.25$ & 20790 \\
\hline April & $13 \pm 0.76$ & 1650 & $1: 1.5$ & 21450 \\
\hline May & $9.45 \pm 0.88$ & 1750 & $2.5: 1$ & 16538 \\
\hline June & 0.00 & 0 & 0:0 & 0 \\
\hline July & $11.7 \pm 2.07$ & 1800 & $1: 1$ & 21060 \\
\hline August & $45.9 \pm 1.34$ & 1550 & $1.1: 1$ & 71145 \\
\hline September & $37.2 \pm 1.88$ & 975 & $2.4: 1$ & 36270 \\
\hline October & $9.45 \pm 0.75$ & 915 & 1:6 & 8647 \\
\hline November & $67.6 \pm 2.14$ & 2503 & $1.9: 1$ & 169203 \\
\hline December & $58.65 \pm 3.68$ & 2580 & $1: 1$ & 151317 \\
\hline Total & & & $1.2: 1$ & 561418 \\
\hline
\end{tabular}

Table 3. Species composition of seahorses landed at various centres of India in 2001

\begin{tabular}{ll}
\hline Landing centres & \multicolumn{1}{c}{ Species } \\
\hline Thondi & Hippocampus borboniensis Dumeril \\
& H. spinosissimus Weber \\
& H. kuda Bleeker \\
& H. fuscus Ruppell \\
& H. trimaculatus Leach \\
Sakthikulangara, Kochi & Hippocampus borboniensis Dumeril \\
and Calicut & H. trimaculatus Leach \\
\hline
\end{tabular}

mean weight $2.92 \pm 1.61 \mathrm{~g}$, and mean length $80 \pm 0.78 \mathrm{~mm}$. The annual seahorse landings at Sakthikulangara harbour was estimated as 561418 individuals (Table 2), which amounted to 1.6 t. Males were numerically dominant in the catch.

The study of species composition of the landings based on morphometric data indicated the occurrence of at least five species of seahorses along the south coast of India (Table 3).

\section{Discussion}

The total annual catch of dried seahorses of $9.75 \mathrm{t}$ determined in the present study was much greater than the $3.6 \mathrm{t}$ estimated by Vincent (1996), based on a brief trade survey. Given the nature of seahorse marketing which involved many stakeholders such as fishers, boat owners, intermediaries and wholesalers engaged in a surreptitious trade, it was difficult to get precise idea or the exact quantity of the seahorses traded by interviews alone. This was emphasised by Vincent (1996) who cautioned that the actual figures could be higher.

A major share of the seahorse catch from India originates from Palk Bay region, which might be the result of the abundance of seagrass and seaweed habitat, favourable for the occurrence of seahorses. The Gulf of Mannar is rocky and offers a less suitable habitat for seahorses. Vincent (1996) reported that Palk Bay contributed $3040 \mathrm{~kg}(84.44 \%)$ of the total annual seahorse trade of $3600 \mathrm{~kg}$ from the south coast of India during 1995. Nevertheless, in the present study the contribution of Palk Bay was assumed only $76 \%$, based on the market surveys. After 1996, there was a steady increase in the quantity and value of seahorses exported from the country. The export figure of $4.34 \mathrm{t}$ of dried seahorses from India worth about 2.7 million rupees in 2001 (Anonymous 2003) is less than half of the estimate of seahorse catch $(9.75 \mathrm{t})$ obtained in the present study. This probably arises because much of the seahorse export from India is channelled through non-conventional routes and is unrecorded. The high demand and attractive price has also probably increased the landings in other centres by attracting more fishing effort for seahorses.

The average dry weight of the seahorses caught from Palk Bay was $2.5 \mathrm{~g}$ in 1995 (Vincent 1996), while in the present study it was $3.68 \mathrm{~g}$. This shows an increase in quantity and size range of seahorse caught from Palk Bay between 1996 and 2001. This might be the result of the conservative estimates arrived from a small quantity of the samples, surveyed for a short period by Vincent (1996), or the improved efficiency by fishers extending the fishing zone to a wider area to meet demand.

Three species of seahorses viz. Hippocampus borboniensis Dumeril, Hippocampus spinosissimus Weber and Hippocampus kuda Bleeker were dominant in the target catch by divers from the south-east coast of India. The shrimp trawl bycatch dominated by Hippocampus trimaculatus Leach from Kerala coast agrees with the 
earlier observations (Vincent 1996), suggesting that it might be a species mostly occurring in deep waters. Lack of an organised fishery and trade on seahorse in the Kerala coast might be because of the small size of seahorses landed or the emphasis being given more to the high-valued shrimp fishery. It was also difficult to segregate a few small-sized seahorses from the huge amounts of bycatch.

The present study showed that the seahorses in the south Tamil Nadu coast are subjected to relatively heavy fishing pressure. The Government of India enforced a ban on the collection of seahorse and sea cucumbers during late 2001, which put thousands of fishers who subsist on these resources for livelihoods into great hardship. The conservation and management of Indian seahorses are currently limited by the absence of data on the abundance and distribution of seahorse species in the region (Sreepada, Desai \& Naik 2002). Thus, serious attempts to study the population and fishery characteristics of seahorses covering the entire coast of India with a view to their conservation are required.

The annual landing of small-sized seahorses wasted as bycatch from Kerala is indicative of the destruction caused by shrimp trawling. Segregating seahorses quickly from the trawl bycatch onboard and returning them to sea could help support conservation of seahorses. Efforts towards conservation of seahorses are required similar to those reported by Vincent \& Pajaro (1997), combined with the popular strategies of fisheries management such as closed seasons, and or delineating marine sanctuaries for seahorses. This would also help to protect the preferred habitats of seahorses, like coral reef areas, estuarine and mangrove areas that are continually being degraded by human interference. Vincent \& Pajaro (1997) reported a novel community-based management programme for sustainable seahorse fishery in the Philippines in which pregnant seahorse males caught were being placed in sea cages in a no-exploitation sanctuary established adjacent to a traditional fishery zone so that the newborn young would escape before the male was sold. Regulating or prohibiting fishing for seahorses during the peak-breeding season (at least during August in Palk Bay region) and regulation of effort (the number of boats in operation during the peak season of availability and the breeding season) could also be considered.

\section{References}

Anonymous (2003) Statistics of Marine Products Exports, 2001. Kochi: MPEDA, 83 pp.

Foster S.J. \& Vincent A.C.J. (2004) Life history and ecology of seahorses: implications for conservation and management. Journal of Fish Biology 65, 1-61.

IUCN (2004) 2004 IUCN Red List of Threatened species. http://www.redlist.org/ (accessed on: 17 March 2005).

Lourie S.A. \& Randall J.E. (2003) A new pygmy seahorse, Hippocampus denise (Teleostei: Syngnathidae), from the Indo-Pacific. Zoological Studies 42, 284-291.

Lourie S.A., Vincent A.C.J. \& Hall H.J. (1999) Seahorses; An Identification Guide to the World Species and Their Conservation. London, UK: Project Seahorse, 214 pp.

Marichamy R., Lipton A.P., Ganapathy A. \& Ramalingam J.R. (1993) Large Scale exploitation of seahorse (Hippocampus kuda) along the Palk Bay Coast of Tamil Nadu, Marine Fisheries Information Service. Technical \& Extension Series 119, 17-20.

McPherson J.M \& Vincent A.C.J. (2004) Assessing east African trade in seahorse species as a basis for conservation under international control. Aquatic Conservation: Marine and Freshwater Ecosystems 14, 521-538.

Sreepada R.A., Desai U.M. \& Naik S. (2002) The plight of Indian seahorses: need for conservation and management. Current Science 82, 377-378.

Vincent A.C.J. (1994) The improbable seahorse. National Geographic, October 1994, 126-140.

Vincent A.C.J. (1995) Exploitation of seahorses and pipefishes. NAGA 18, 18-19.

Vincent A.C.J. (1996) The International Trade in Seahorses. Cambridge, UK: TRAFFIC International, 163 pp.

Vincent A.C.J. \& Pajaro M.G. (1997) Community based management for sustainable seahorse fishery. In: D.A. Hancock \& D.C. Smith (eds) Developing and Sustaining World Fisheries Resources: The State of Science \& Management. Brisbane, Australia: CSIRO, World Fisheries Congress, pp. 761-766.

Vincent A.C.J. \& Sadler L.M. (1995) Faithful pair bond in wild seahorses, H. whitei. Animal Behaviour 50, 1557-1569. 